\title{
Profound Hypoglycemia and Convulsion, Think About Ecstasy Poisoning
}

\author{
Dr. Mohamed Mattous ${ }^{1 *}$, Dr. Nabil Jbili ${ }^{1}$, Dr. Lotfi Bibiche ${ }^{1}$, Dr. Jaouad Laoutid ${ }^{2}$
}

${ }^{1}$ Service de Réanimation Médicale de l'Hôpital Militaire Moulay Ismail Meknès Marocco

${ }^{2}$ Chef de service de Réanimation Médicale de l'Hôpital Militaire Moulay Ismail Meknès Marocco

DOI: $10.36347 /$ simcr.2020.v08i02.046

| Received: 10.02 .2020 | Accepted: 17.02.2020 | Published: 29.02 .2020

*Corresponding author: Mohamed Mattous

Abstract

Ecstasy or MDMA (Methylene Dioxy Met Amphetamin) is a synthetic drug commonly used by young people for its stimulating and euphoric effect, it can however be responsible for side effects including hyperthermia, psychomotor agitation, cardiotoxicity, hepatotoxicity, hypoglycemia, renal failure, hyponatremia and seizures. We report a clinical observation of a 34-year-old patient who experienced profound hypoglycemia and convulsive hyponatremia following ingestion of an ecstasy tablet. The deep hypoglycemia is thought to be due to endogenous hyperinsulinémie requiring close monitoring of blood sugar in any patient admitted for ecstasy poisoning and a dosage of serum insulin and Cpeptide in patients with hypoglycemia. Hyponatremia can be explained either by a direct action of ecstasy or by excessive consumption of water(dilution hyponatremia ), it can cause , when it is deep, a cerebral edema which would explain the seizures, of or the advantage of ingesting water simultaneously to prevent dehydration or ingesting salt at the same time as reduced volumes of water.

Keywords: Profound hypoglycemia, hyponatremia, convulsion, ecstasy.

Copyright @ 2020: This is an open-access article distributed under the terms of the Creative Commons Attribution license which permits unrestricted use, distribution, and reproduction in any medium for non-commercial use (NonCommercial, or CC-BY-NC) provided the original author and source are credited.

\section{INTRODUCTION}

Ecstasy or MDMA (Methylene Dioxy Met Amphetamine) is a synthetic drug commonly used by the young subject for its stimulating and euphoric effects [1], however this molecule is not free from side effects namely hyperthermia, psychomotor agitation cardiotoxicity, hepatotoxicity, hypoglycemia, renal failure, hyponatremia and seizures [2]. We report a clinical observation of a 34 year old patient who experienced profound hypoglycemia and convulsive hyponatremia following ingestion of an ecstasy tablet

\section{Clinical Observation}

This is a 34 year old patient with a history of chronic smoking at the rate of 14 packs/year and occasional alcoholism, who was admitted to the emergency reception service for generalized tonicclonic seizures with revulsion of the eyes, bite if the tongue and leaking of urine following the ingestion of an ecstasy tablet. The emergency response consisted of monitoring vital parameters (TA, HR, FR, SpO2), a position in the left lateral decubitus position, oxygen therapy in a high concentration mask (10 litres/min) and an intramuscular injection of diazepam $10 \mathrm{mg}$. The clinical examination after this initial management and after the cessation of the convulsions found an apyretic patient (temperature at $37,7^{\circ} \mathrm{C}$ ), hemodynamically stable (BP at $13 / 6 \mathrm{mmHg}, \mathrm{HR}$ at 110 beats $/ \mathrm{min}$ ) and respiratory (FR at 18 cycles/min, $\mathrm{SpO} 2$ at $100 \%$ under oxygen), the Glasgow score was difficult to achieve (the diazepam effect) and the neurological examination had not found any postcritical sensitivomotor deficit. Capillary blood sugar was very low at $0,25 \mathrm{~g} / \mathrm{l}$ and the administration of $50 \mathrm{ml}$ of $30 \%$ glucose serum was done urgently. The additional examinations carried out showed hyponatremia at $113 \mathrm{mmol} / \mathrm{l}$, calcemia at 2,4 $\mathrm{mmol} / \mathrm{l}$, a slight increase in $\mathrm{CPK}$ at $205 \mathrm{IU} / 1$, cerebral edema on CT and the presence of ecstasy in the blood and the urines. The additional treatment consisted of correcting hyponatremia with saline solutions $(0,5$ $\mathrm{mmol} / \mathrm{l} / \mathrm{h}$ ), the evolution was marked by the elevation of the blood level to $138 \mathrm{mmol} / \mathrm{l}$, of the blood sugar to $1,04 \mathrm{~g} / \mathrm{l}$, the stop of the convulsion and recovery of consciousness.

\section{DISCUSSION}

Deep hypoglycemia secondary to ecstasy poisoning has been reported in humans and is believed to be due to endogenous hyperinsulinémie according to one study [3]. This requires close monitoring of blood glucose levels in any patient admitted for ecstasy poisoning and the determination of serum insulin and C-peptide in patients with hypoglycemia. Hyponatremia 
can be explained either by a direct action of ecstasy or by excessive consumption of water (dilution hyponatremia) [4]. This deep hyponatremia can lead to a cerebral edema which would explain the convulsive crises observed in our patient. The latter may be due, according to a study, to the direct toxic effect of ecstasy on the axons of serotonergic neurons or to damage to the central nervous system according to the other authors [5, 6], hence interest in ingesting water simultaneously to prevent dehydration, other authors recommend ingesting salt along with reduced volumes of water. The realization of a hydroelectrolytic assessment is essential in front of any poisoning with ecstasy and if the patient presents a hyponatremia with convulsive crises it is necessary to first control the crises by benzodiazepines and think of simultaneously correcting the hyponatremia by administration venous saline solution [7].

\section{CONCLUSION}

In the event of any profound hypoglycemia or seizures or combination of the two, think of intoxication with ecstasy and start treatment early to avoid serious complications which can be life-threatening for the patient.

\section{REFERENCE}

1. Kalant H. The pharmacology and toxicology of 'ecstasy' (MDMA) and related drugs. Canadian Medical Association Journal. 2001; 165(7):917928.

2. Ben-Abraham R, Szold O, Rudick V, Weinbroum AA. "Ecstasy" intoxication: life-threatening manifestations and resuscitative measures in the intensive care setting. European Journal of Emergency Medicine. 2003; 10(4):309-313.

3. Carrera P, Iyer VN. Profound hypoglycemia with ecstasy intoxication. Case reports in emergency medicine. 2015;2015.

4. Parr MJ, Low HM, Botterill P. Hyponatraemia and death after "ecstasy" ingestion. Medical Journal of Australia. 1997 Feb;166(3):136-7.

5. Gudelsky GA,

Yamamoto BK, Nash JP. Potentiation of 3,4ethylenedioxymetamphetamine-induced dopamine release and serotonin neurotoxicity by 5-HT2 receptor agonists. Europian Journal Pharmacol, $1994 ; 264: 325-330$.

6. Green AR, Goodwin GM. Ecstasy and neurodegeneration. BMJ, 1996; 312:1493.

7. Wilkins B. Hyponatraemia must be treated with low water input. BMJ, 1996; 313:689-690. 